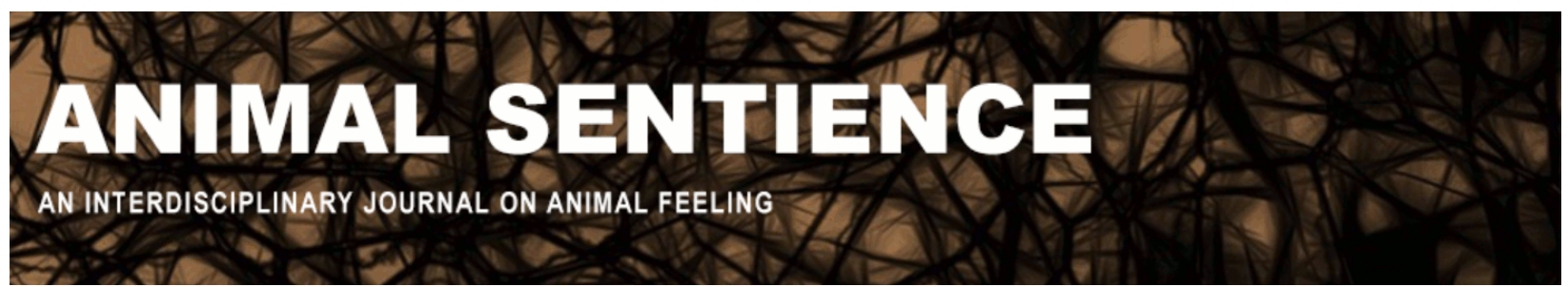

$\mathrm{Ng}$, Yew-Kwang (2016) Utilitarianism generalized to include animals. Animal Sentience 7(19)

DOI: $10.51291 / 2377-7478.1115$

Date of submission: 2016-06-27

Date of acceptance: 2016-07-10

(c)

This article has appeared in the journal Animal

Sentience, a peer-reviewed journal on animal

cognition and feeling. It has been made open access,

free for all, by WellBeing International and deposited

in the WBI Studies Repository. For more information,

please contact

wbisr-info@wellbeingintl.org.

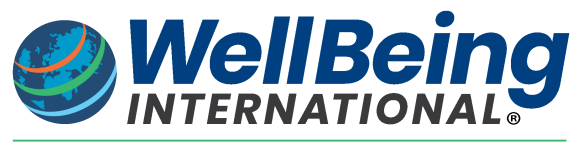

SOLUTIONS FOR PEOPLE, ANIMALS AND ENVIRONMENT 


\title{
Utilitarianism generalized to include animals
}

\author{
Response to Commentary on $\underline{\mathbf{N g}}$ on Animal Suffering
}

\author{
Yew-Kwang Ng \\ Division of Economics \\ Nanyang Technological University, Singapore
}

\begin{abstract}
In response to the seventeen commentaries to date on my target article on reducing animal suffering, I propose that the term "welfarism" (when used pejoratively by animal advocates) should be qualified as "anthropocentric welfarism" so as to leave "welfarism" simpliciter to be used in its generic sense of efforts to improve conditions for those who need it. Welfarism in this benign sense - even in its specific utilitarian form (maximizing the sum total of net welfare) with long-term future effects and effects on others (including animals) appropriately taken into account - should be unobjectionable (even if not considered sufficient by all advocates). Rights, both animal and human, should be similarly grounded in the promotion of welfare. My strategic proposal to concentrate on reducing the suffering of farm animals now has been criticized as putting human interests above those of animals and as ignoring the suffering of animals in the wild. These criticisms misunderstand my position and fail to distinguish between the short and long run or between strategy and ideal morality. My position is consistent with perfect impartiality between animals and humans at the level of ideal morality. I also respond to the extreme asymmetrical focus on reducing suffering, ignoring the moral importance of pleasure (the argument against trading off "my orgasms against others' agony"). Even mild measures for reducing animal suffering such as enlarging cage size for factory chickens and prohibiting the cutting of live eels have to be based on some interpersonal and interspecies comparisons of welfare. We must not use the philosophical uncertainty about the comparability or the very existence of animal sentience to diminish our efforts to protect animal welfare.
\end{abstract}

Keywords: animal rights, animal suffering, welfarism, utilitarianism, welfare biology

\begin{abstract}
Yew-Kwang Ng ykng@ntu.edu.sg, Winsemius professor in economics, Nanyang Technological University, is a fellow of the Academy of Social Sciences in Australia and Distinguished Fellow of the Economic Society of Australia. His recent books include: Common Mistakes in Economics by the Public, Students, Economists and Nobel Laureates (open access); and Happinessism. http://www.ntu.edu.sg/home/ykng/
\end{abstract}

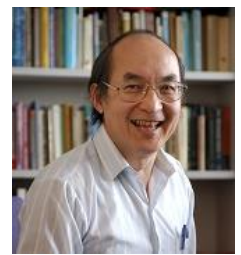

I am glad that my target article ( $\underline{\mathbf{N g} 2016)}$ has so far attracted 17 commentaries from animal advocates (Lori Marino), animal charity evaluators (Allison Smith \& Jacy Reese), animal and bioethicists (Catia Faria, Oscar Horta, Loel Marks Lessica Pierce), biologists (Marc Bekoff, Liv Baker), environmentalists (Simon Leadbeater), philosophers (Stijn Bruers, Stephen R. Clark, Kyle Johannsen, Eze Paez, Bernard Rollin, Beril Sözmen), an attorney

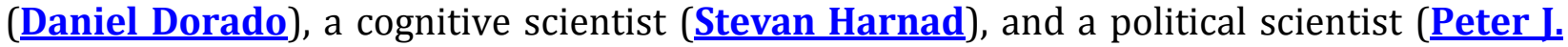
Li). I am grateful to them for their involvement. Rather than responding to separate commentaries in turn, I will largely focus on separate issues in turn. 


\section{Welfarism vs. Anthropocentric Welfarism}

A repeated theme in the commentary is that I am a welfarist putting human interest above that of animals. For example: "Ng assumes, quite in line with the broader ideology of animal welfare, that human industry is more important than the well-being of animals. This has been called "welfarism" (Bekoff \& Pierce 2016). This is a big misunderstanding of my position. Before explaining why, I have to make an important terminological distinction.

The original term "welfarism" as traditionally used by philosophers and economists does not have the connotation of anthropocentricism. Welfarism just means that what is of ultimate importance/value is the welfare of sentient organisms (human or animal). Moreover, most economic and philosophical problems have been discussed independently of animal welfare. This independent discussion does not entail that animal welfare is not important, as the level of animal welfare may be held unchanged conceptually to focus on non-animal issues. The point here is that the traditional term "welfarism" just means that it is welfare that is of ultimate value. In its pure form (to which I subscribe), ultimately speaking, it is welfare only that is of intrinsic value. In this sense of welfarism, I am a 100\% welfarist. I am in fact also a utilitarian, believing that, for human society (ignoring issues of animal welfare, see below), the morally acceptable ultimate objective is to maximize the unweighted (or equally weighted) sum of individual welfares. (Thus, Johannsen's observation that I am a "self-proclaimed utilitarian" is correct.) Welfarism makes perfect sense. If not, why are we concerned only with human rights and animal rights, and not with stone rights and table rights? What is not susceptible to welfare is not of (direct and intrinsic) moral importance. (For a fuller defence of welfarism and utilitarianism, see $\mathrm{Ng}$ 1975, 1990, 2013.)

To see the importance of welfarism, consider a non-welfarist ethicist who believes the following: We should be moral only towards those who have morals; animals (perhaps excluding some higher primates?) have no morals. So we do not have to care about animal welfare. We may inflict suffering on them without being immoral. If he believes in this as his ultimate categorical imperative, I do not think I can argue against him or persuade him of the importance of caring for animals before I can persuade him to give up his arbitrary imperative and convince him of the acceptability of welfarism.

In animal rights circles, at least among the stronger advocates, "welfarism" is used in quite a different sense. For example, Doris Lin, an animal rights attorney and Director of Legal Affairs for the Animal Protection League of New Jersey, defines welfarism as follows:

Welfarism is the belief that humans have the right to use animals as we see fit as long as they are treated humanely. There may be some uses where the benefit to humans is recognized as trivial compared to the amount of animal suffering, such as dogfighting or fur, where the use is believed to be unjustified. The term "welfarist," as an adjective, is used pejoratively by animal rights advocates to refer to a situation where animals will continue to be used with very minimal improvements in the care, confinement or slaughter of the animals (Lin 2016). 
This pejorative sense of welfarism is consistent with Bekoff \& Pierce's usage. I am not a welfarist in this sense. In my target article I do not assume that human industry is more important than animal welfare. For utilitarian calculations, importance does not depend on species but on the relative size of the welfare gains and losses involved.

Since the original concept of welfarism does not imply anthropocentrism, the pejorative sense of "welfarism" as it is used by some animal rights advocates is misleading and confusing. I would accordingly suggest calling this kind of welfarism "anthropocentric welfarism," reserving the generic term "welfarism" for the traditional non-derogatory sense of the term. This may not only reduce misunderstanding but could well increase the potential influence of animal rights advocates. I think a welfarist like myself should be regarded by the animal rights advocates as a potential convert rather than as an enemy, if not already a strong ally or even one of them. Using "welfarism" pejoratively tends to alienate welfarists. "Welfare" is definitely something good; "welfarism" must not be used pejoratively.

Some welfarists may be anthropocentric, but not all welfarists need be. Welfarism itself is quite consistent with perfect impartiality between animal and human welfare. I cannot myself claim such perfect or even "near" perfect impartiality even towards my fellow humans. However, in terms of ideal morality in the formal sense, I have adhered to impartiality towards all people (for the case of animals, see below) and even potential future people not yet born (Ng 1989, 2005). Most economists (indeed most social scientists and policy debaters) do their analysis without considering a possible change in the set of people concerned. For the minority who do, most regard unborn people as not having any rights. I had a heated debate with a Nobel laureate in economics, John Harsanyi, on this (Ng 1983). Though I have not formally written on animal-human impartiality, I accept this impartiality at the level of ideal morality. Ideal morality is not the same as practical reality, however. It would be ideal if we could treat animals impartially, but as a species, as nations and as individuals, we have our own interests, and in reality there are conflicts of interest in which some sentient suffering is inescapable.

I do not pretend to be a morally perfect person in practice, but the moral philosophy I believe in (simply put: net welfare maximization for all sentients) is arguably perfect, at least as far as I can see. It should of course be subject to criticism and, if needed and possible, to improvements (though I have yet to see convincing argument of a need for improvement). Nevertheless, going from ideal morality at the philosophical level to the practical level, individuals (myself included) and societies may be partial towards their own welfare. None of the points made in my target article, however, is based on this possible partiality. All are consistent with a welfarism that is perfectly impartial between animals and humans. 


\section{Ideals vs. Practical Strategies; Short vs. Long Runs}

The main reason my target article is consistent with perfect impartiality is that it outlines practical strategies to achieve our objective of reducing animal suffering or improving animal net welfare in the short run; it does not expound ideals. The article suggests that, to have (relatively) fast successes in achieving our objectives, the strategies proposed are likely to be productive, partly because they do not impose high costs on humans and partly because this makes them more likely to be acceptable to the majority. I am not arguing that we should not do more than what I have proposed, especially in the longer run. Thus, many of the critical points made by my commentators are not inconsistent with my own position; it is just that there is often some misunderstanding of what my position is. For example, Bekoff \& Pierce write: "While Professor Ng clearly sees the need to address animal suffering, he aims far too low and stops far short of the goal, and in the end favors continuing to use the paradigm of animal welfare along with its various loopholes that favor human interests over those of other animals. Surely we can and must do more." But doing more is consistent with my position; my target article does not "favor human interests over those of other animals."

While many proposals made by the commentators are consistent with my target article, I must admit the possibility that I am being too pessimistic here in thinking that many proposals are unlikely to be practicable, at least in the fairly long "short run." I thought I was born optimistic; indeed, I've often been regarded by others as being too optimistic, both academically and personally. I lose money in the share market by being too optimistic and have not learned from this knowledge to rectify my over-optimistic inclination. (Thus, I lost money again in the last round of share-market decline; in fact, I lost so much that I have even had to postpone my payments to an animal ethics group in sponsoring a matching donation!) However, I find many proposals unlikely to be practically feasible, at least not for a very long time. For example:

1. 'To eradicate suffering in the poultry industry requires the elimination of the industry itself" (Leadbeater 2016). This may be true but it is unlikely to be practicable. Nor is "the eventual abolition of animal agriculture" ( $\underline{\text { Smith \& Reese }}$ 2016) likely to be practicable any time soon. Before the poultry industry or even the whole of animal agriculture can be eliminated, we still need to work to eliminate the appallingly small cages, etc. While we work to abolish all cruelty, let us also work to reduce it.

2. "Although livestock and slave welfare improvements might be low-cost, quick-win measures, they are far from sufficient ethically" (Bruers 2016). Agreed; but even the quick-win battles are far from having been won yet.

3. "Ng underestimates the potential benefits of advocacy for wild animals in terms of net reduction in suffering perhaps because he is overestimating people's resistance to caring about wild animals and to intervening in nature on their behalf" (Paez 2016). I wish I were "overestimating people's resistance," but could Paez be underestimating it? 
4. "Analyses by meta-charities suggest that vegan outreach is a more effective strategy to help farmed animals. This is the strategy of convincing individuals that they must cease to consume animal products, for the sake of the animals themselves" ( 2016). It would be good and indeed admirable if this could be successful on a large scale and if the reduction in human welfare, if any, were more than offset by the gain in animal welfare. But I really cannot pin too much hope on this, despite my optimistic tendencies.

\section{Animal Welfare vs. Animal Rights}

The fact that I am a welfarist (in its original sense, without entailing anthropocentricism) does not mean that I do not believe in rights. However, being a welfarist, I believe that rights, whether human or animal, should, at least ultimately speaking, be for the sake of enhancing welfare. The insistence on certain human or animal rights may be a good strategy for reducing suffering and hence good for the promotion of welfare in the long run. Insisting on the fundamental importance of human and animal rights at the practical or political level may also be good - read "long-run welfare maximizing" - to avoid compromising these rights for short-term welfare or other interests to the detriment of welfare in the long run. However, at the fundamental level of moral philosophy, rights for rights' sake do not make sense to me. Whether in the form of human rights, animal rights, the Kantian categorical imperative, moral principles or what not, these should ultimately be based on welfare considerations.

For example, for hundreds of years, people in ancient China believed in the intrinsic moral principle of "one woman should not serve two men/husbands" (一女不事二夫) such that a woman should not remarry even long after the death of her husband. Allowing such intrinsic moral principles or categorical imperatives irrespective of their contribution to welfare resulted in huge suffering. After prolonged criticism, including by many novelists, this damaging imperative was given up as wrong. Did this sort of thing only happen to ancient people? Couldn't it happen today? Even right now, as reported early in April 2016, we have many thousands of so-called honour killings (typically by brothers or cousins killing their sisters/cousins for falling in love with men) each year in a single country like Pakistan. Does this only happen in underdeveloped countries? Euthanasia is still illegal almost worldwide (with the exception of the Netherlands), even for doctors helping suffering patients who have chosen to end their miserable and hopeless lives. Intrinsic/categorical principles not justified by welfare considerations are causing enormous suffering right now worldwide even just within our own species.

I am willing to accept the formulation of rights, but only for the promotion of long-term welfare, human or animal. Doing a cost-benefit analysis each time a decision has to be made is impractical and too costly, so adopting certain rights-based rules and laws may be welfare enhancing. This may be true for our personal routines, human relationships, national affairs, and human-animal relationships. However, our decisions about whether these rules or laws should be introduced, sustained or rejected should ultimately be based on long-term welfare considerations. Accepting intrinsic principles or categorical imperatives irrespective of their contribution to welfare may lead - and has led - to 
enormous suffering, as pointed out in the examples in the preceding paragraph. They should definitely be rejected.

Since we almost certainly have more than just one single rule/principle/law to guide us, what should we do when one rule is in conflict with another? Which rule should we give up? As once happened when a radio announcer made a racist remark, should he be allowed to do so based on the rule protecting free speech or should he be stopped or penalized for violating the rule forbidding racism? When rules conflict, the reasonable ultimate principle to judge which rule to follow should again be long-term welfare, taking likely side effects into account as much as possible. But whose welfare? For a social problem not concerning animals, it should be the welfare of all individuals in the society, counting the welfare of each individual impartially (which is satisfied by, but not only by, utilitarianism). For problems involving animal welfare, too, overall welfare should be taken into account. My target article does not abandon the option of impartiality here: Animal and human welfare should be treated similarly, at least at the level of ideal morality. However, at least in the near term, we are unlikely to be able to achieve or even approach this ideal. If we were able to persuade human society to treat animal welfare as having even just $1 \%$ the importance of human welfare, we should long have banned countless gratuitously cruel practices such as cutting living eels in half, imposing heavy penalties on violators without hesitation.

\section{Stevan Harnad's Critique of Utilitarianism/Welfarism}

I am a self-professed utilitarian both in human public policy (abstracting from animal welfare) and in animal welfare issues, as mentioned above. Ideally, we want to have high net welfare, human or animal. Of course, there could be interpersonal and interspecies conflicts. However, as ultimately only happiness is of intrinsic positive value and pain is of intrinsic negative value, we should want high net welfare. I may want higher net welfare for myself, but society should be impartial and take the net welfare of everyone as equally important. If we are not homocentric, we should also consider animal welfare. This is roughly what I regard as utilitarianism, as generalized to include animal welfare. (In fact, the great utilitarian Bentham was also a champion of animal rights. Subsequent discussion of utilitarianism, however, focused largely on human individuals.) If not utilitarianism, we should at least want welfarism: Strictly speaking, utilitarianism requires the less widely acceptable criterion of maximizing the unweighted or equally weighted sum of individual welfares. Most of my arguments depend only on welfarism, not utilitarianism. However, Harnad's commentary casts serious doubt both on the moral basis and practicability of utilitarianism and welfarism. Two or three separate though somewhat related points are involved.

First, at some points (see qualifications below), Harnad seems to regard pain and pleasure as incommensurable, suggesting that they cannot be traded off against each other, contrary to both utilitarianism and common sense. Even a mouse has the common sense of trading off pain and pleasure, as when it decides to cross a strip of painful electric shock to obtain the pleasure of electric stimulation of the pleasure center in its brain (Jacques 1979). We make similar trade-offs all the time, though a good decision maker should take into account not only immediate effects but also side- and long-term effects; an ethical decision maker 
should take account also the effects on others, including animals. Thus, I fail to see the incommensurability of pain and pleasure at least in principle, though the actual comparison involves difficulties.

However, Harnad does not mean incommensurability for oneself, only interpersonally: "To put it another way, orgasms cannot be traded off against agony. I can do it for myself, deciding how many lashes I would personally endure in exchange for how many orgasms. But no one else can judge that for me; I doubt that any two individuals would agree on their personal trade-offs. And there's certainly no way to trade off my orgasms against others' agony in some sort of integrated pain/pleasure formula purporting to maximize net welfare for a population."

The question of "my orgasms against others' agony" at least involves: (1) The question of self-interest vs. the welfare of the group, briefly touched on above (and below); (2) the feasibility of interpersonal comparison of welfare. I have argued for the interpersonal comparability of welfare, at least in principle, though acknowledging some practical difficulties which will be gradually overcome as our knowledge advances (Ng 1997, 2015). Discussion of issues of animal welfare has to be based on some degree of interspecies comparison of welfare as well. If we deny any such comparison, one could make the anthropocentric argument: "How could you inflict on me the pain of eating less meat in order to increase the comfort of factory chickens?"

Most changes (including but not confined to those related to animal welfare) are not Paretian (Arnold 2015; Cowen 2005). A Paretian change makes all sentient individuals (including animals) better off (i.e., having higher levels of net welfare) or at least no worse off. For most changes, some individuals are made worse off. Such changes may still be justified morally if more individuals are made better off, and to a greater degree, taking all effects into account. But this requires the interpersonal/interspecies comparison of welfare gains and losses (or orgasms and agonies). If we refuse to make these comparisons, we are likely to be stuck with the status quo. Even the mildest proposals made in my target article - such as increasing cage size for factory chickens and prohibiting the cutting of live eels are likely to incur some adjustment costs and will make some individuals worse off, at least in the short run. Though actual inter-individual comparisons may be difficult to make and subject to imperfect accuracy, we must not use the philosophical doubt about comparability to impede our protection of animal welfare, just as we should not use the minute possibility of the non-existence of animal sentience to hinder our concern for animal welfare. (Obviously, being the founder of Animal Sentience, Harnad is in agreement with me on the latter; perhaps he could also be persuaded by my position on the former?) The precise maximization of the aggregate sum of net welfare may be impossible in practice, but it is still desirable to have more net welfare rather than less, even if imprecisely.

I also argue elsewhere that beliefs about the impossibility of comparing welfare interpersonally and about the unacceptability of utilitarianism are based on a nonmaterialist solution to the theory of mind, i.e., on the existence of souls. The compellingness of the theory of evolution and of some discoveries in brain science (including the split-brain experiments) render (philosophical) materialism very persuasive. Accepting materialism 
implies that the self is not significant. (There is no substantive reason to care much more about the welfare of one's own future self than the welfare of others, but few individuals, myself included, can escape the fitness-enhancing and naturally selected inclination to care much more about oneself.) Materialism also implies that it is possible to compare welfare across individuals, and is makes utilitarianism compelling. Moreover, even the existence of souls would not necessarily rule out comparability or utilitarianism ( $\mathrm{Ng} \mathrm{1992).}$

There is also the moral issue. Harnad regards pain or suffering as the sole welfare and moral concern; pleasure is morally irrelevant. (This may be called extreme negative utilitarianism/welfarism.) As he puts it, "What happens in a world of pleasure zombies is as morally irrelevant as what happens in a world of insentient zombies or a world of rocks." I would certainly strongly prefer to be a pleasure zombie rather than either an insentient zombie or a rock. If I were a pleasure zombie, I would also certainly want to have more rather than less pleasure (holding the net welfare levels of all other sentients unchanged). It is an important concern to me, and I think it should also be of moral concern to a zombie society that includes me.

In Harnad's view, "the only welfare calculations that matter are the ones that minimize pain, factoring in pleasure only to the extent that being deprived of pleasure may sometimes be painful." Thus, if we keep side effects on others and in the future to zero for simplicity of comparison, and include all effects (including the pain from deprivation of pleasure) in the comparison below, Harnad would prefer (or at least would think that morally one should prefer) a life of A: 100 units of pain plus one unit of pleasure, to B: 101 units of pain plus ten trillion units of pleasure, because A has less pain. I and most people have no hesitation in choosing B (as the stimulation-seeking mouse also would) either for ourselves or for some other individual or society (with everyone having the same pain-pleasure profile in either A or B above). (Readers having doubts on the possibility of speaking of units of pain and pleasure may consult the literature on just-perceptible differences (Weber 1834; Dennis 1948); see, e.g. Edgeworth 1881 and Ng 1975.)

Another point for consideration: If only the minimization of pain were important and the maintenance and promotion of pleasure were not, would the instantaneous destruction of the whole world not be the best alternative? All pains would be minimized to zero. Though all pleasures would also vanish; they are not important!

Yet another related point: If we cannot measure, compare, and even guestimate welfare inter-individually (including human and animal individuals), how are we going to make the following choice? Suppose (perhaps because of resource limitations) we can only choose between: $X=$ increase the cage size for all farmed chickens by a certain amount versus $Y=$ keep the cage size unchanged, but convert a fraction (e.g., half) of all factory-farmed chickens into free-range chickens? (For simplicity, assume no effects on others and no indirect effects; only the welfare of the chickens is affected.) Even if we agree with Harnad that the objective should be to minimize pain, which alternative has less pain? Before choosing between $\mathrm{X}$ and $\mathrm{Y}$, I would like to know or at least guestimate the amount of pain reduction both from (1) having the larger cage size and from (2) converting from the larger cage size to free range for the other half of the chickens. If we have to compare the amount 
of pain reduction for different chickens, we may also have to compare orgasms and agonies for different individuals for many other choices.

Harnad and I appear to be in agreement on the point that it is sentience (i.e., the felt states of feeling organisms) that is of moral importance, not the unfelt states of insentient organisms, hypothetical zombies or inanimate rocks. However, while I regard both pain and pleasure as equally important and valuable, one having negative and the other positive value, Harnad has an extreme asymmetrical view. Harnad's moral imperative of only minimizing pain, without including pleasure in the welfare or moral consideration is the most extreme one I have encountered. However, the less extreme, but still stronger emphasis on the importance of pain reduction in contrast to pleasure enhancement is widespread in moral philosophy, both for the academic world and the general public. This asymmetrical treatment of pain and pleasure (assigning higher importance of pain avoidance) appears to be inconsistent with utilitarianism. I accept this asymmetrical treatment at the level of practical living, business, laws, etc. on the grounds of the likelihood that the indirect effects of pain reduction on future welfare would be larger than those of pleasure enhancement. For example, either bodily pain or mental suffering is likely to cause negative effects on us, reducing our future welfare. In addition, harming others is likely to create interpersonal conflicts, social disharmony, etc. which are very detrimental to longterm welfare. On account of these practical considerations, it may be desirable to have certain legally protected rights (to avoid pain infliction) that should be largely (but not totally) immune from short-term considerations. However, why some rights and not others? Such considerations ultimately have to be justified on the basis of long-term welfare, as argued in the previous section. Nevertheless, at the fundamental level of moral philosophy, after taking all effects in the future and on all sentients into account, a world of higher net welfare is a better world. So, there is no violation of utilitarianism.

Utilitarianism is fine; it just has to be sophisticated. Not focusing only on oneself and on the present, it must also take into account the future, other people, and other sentients. However, because of the importance of the asymmetrical emphasis on pain avoidance at the practical level, many people, including accomplished moral philosophers have been (in my view) misled into believing in the asymmetrical treatment for its own sake, regarding utilitarianism as an unacceptable moral position.

\section{Some Interesting Points and Some Misunderstandings/Clarifications}

A point that is of both conceptual interest and practical importance is raised by Bruers: "The strategy of transforming the livestock sector with animal welfare improvements often results in a trade-off with environmental goals....Less intensive production (e.g., slower growth of animals) is better in terms of animal welfare but also results in decreased resource efficiency and hence a bigger ecological footprint." As an economist, I know my preferred way to tackle this problem.

If we impose sufficient taxes on important sources of external costs (costs imposed on others including the whole world, without compensation) including pollution and emission of greenhouse gases or other contributors to the ecological footprint, we may proceed with 
animal welfare regulation on its own merits, without worrying about its indirect impact on the ecology. Under this proposal, all users of resources/processes have to pay for both the direct and indirect costs. The pursuit of their own self-interest would then result in socially efficient usage. Taxes on external costs are not my proposal but that of Arthur Pigou (1912/1932) a century ago (See Ng 2004a, Ch. 7 for a discussion). The Pigovian taxes are in accordance with the amount of damage imposed on others. Many people, economists included, think that these are impossible to estimate, especially for issues like global warming, which concern the whole world for centuries into the future. However, it is desirable to tax external costs (at least) at the marginal costs of abating the environmental disruption; and these costs are easier to estimate than the marginal damage of disruption. Moreover, these taxes will normally yield total revenue in excess of the optimal amount of abatement spending, as shown in Ng (2004b).

A number of commentators (including Bekoff \& Pierce, Baker, and Leadbeater) mention the point about the less than $100 \%$ certainty about animal suffering. I mentioned this mainly because I was trying to argue for the feasibility of studying animal welfare despite the paradox (related to this lack of certainty) emphasized by Dawkins (2014). Thus, rather than intending to justify ignoring animal suffering for lack of $100 \%$ certainty, I just pointed out that we also lack $100 \%$ certainty about the welfare of our spouses! Let me try to put this another way. Suppose we are $99.9999 \%$ certain of the welfare susceptibility of our fellow humans and, say, even 1,000 times (probably an over-estimate) less certain of that susceptibility in chickens. That means that we are still $99.9 \%$ certain. Surely, we should not relinquish our responsibility for chickens on that $0.1 \%$ probability that they may not suffer. Though $99.9999 \%$ and $99.9 \%$ involve a difference in the degree of certainty of 1,000 times, the probability of uncertainty involved is still less than $0.1 \%$ which is surely far too small to justify ignoring animal welfare.

Before we are willing to fly, we need a certainty of safety of $99.99 \%$ or more (I would require more than $99.9999 \%$ safety unless the flight is unusually important). Even if chickens are 1,000 times less important than ourselves, we should need at least 90\% certainty of non-feeling before we should largely ignore their possibility of suffering. Even a $10 \%$ or $5 \%$ likelihood of large suffering should not be completely ignored, not to mention $90 \%$ or $99.9 \%$. For practical purposes, instead of philosophical musing, we should take the animal welfare needs of all mammals and most if not all vertebrates as if it were certain, i.e., we should ignore the difference (of less than $0.1 \%$ ) between $99.9 \%$ and $99.9999 \%$ for simplicity.

Harnad also mentions probability; I have no problem in giving "the other mind the benefit of the doubt"; I thought my target article and my current response above went much further than that. (Stevan Harnad's commentary is partly, if not mainly, commenting on my response, not just my target article.) However, my position here could be misinterpreted to mean the opposite of what I intend, if not read carefully.

A related clarification: I agree completely that "the condition on which the applicability of moral concern depends "is not a capacity to think, but a capacity to feel (i.e., sentience)" 
(Lohannsen). I have never held "the view that such cognitive abilities are necessary for full moral standing."

I do not understand the usage of some commentators of "welfare" in contrast to "well-being." For example, Bekoff \& Pierce call for "Replacing the science of animal welfare with the science of animal well-being"; Baker calls for "moving toward a 'science of animal wellbeing'....As in human research on well-being, a science devoted to the well-being of animals should be asking 'what makes life worth living?'."

I regard my welfare as identical to my well-being which is my net happiness (enjoyment minus suffering, both interpreted in the wide sense inclusive of bodily and spiritual feelings). We tend to use happiness less informally and to refer to current feelings and use welfare or well-being (or subjective well-being) more formally and to refer to longer-term feelings. If we ignore the degree of formality and hold the period constant, I see absolutely no difference in my (net) happiness, welfare or well-being. If we ignore the contributions towards the welfare of other individuals (human and animal), what makes life worth living is the welfare of that individual. Even for contributions towards others, they should be in terms of welfare. Ultimately speaking, only happiness or welfare is of intrinsic value ( $\mathrm{Ng}$ $1990,2013,2015)$. I thus fail to see the difference between the science of animal (or human for that matter) welfare and the science of animal well-being. I await enlightenment.

I can see that some commentators may be using "well-being" in some more objective sense, such as being in good health and exhibiting normal behaviour. However, a person could be in good health but very unhappy for various reasons; the normal conditions for most animals could still mean large negative net welfare ( $\mathrm{Ng} \mathrm{1995).} \mathrm{Being} \mathrm{healthy} \mathrm{now} \mathrm{may} \mathrm{be}$ important for a long and happy life; but it is the total net welfare (plus any contribution towards the increase in net welfare of others, animal or human) that is of value. When we do not have good indicators for health, we may use cruder indicators such as size; when we do not have good indicators for welfare, we may use indirect indicators such as health. However, regarding the moral issues of animal rights and welfare, the ultimate concern should be with welfare, not with cruder indicators such as health or "well-being" (if defined to be different from welfare). If we could go to the ultimate level of welfare, as my target article, my 1995 paper and many other animal advocates argue, then using the cruder concepts of health or other indicators of objective well-being, though probably serving certain other purposes where useful, would be a retreat, not an advance, at least in the sense of the depth of analysis or the level of ultimate moral concern.

Some quick points for clarifications:

- 'Ng's phrase 'virtually costless' is troublesome because there are always costs to the animals" (Bekoff \& Pierce). I use "costless" to refer to the costs on humans, not the costs to the animals. If we could substantially reduce animal suffering at little or even negative costs on humans, should that not be definitely done? But I never say that we should not do more.

- "The life of every individual matters" (Bekoff \& Pierce). I disagree. What matters is the property of sentience (i.e., feeling) of sentient living individuals, not just the property of 
being a living organism. Presumably not all living things feel. Feeling and mattering are inextricably related. Nothing matters to or about an unfeeling rock (as Harnad also apparently agrees). Just the fact of living does not matter intrinsically in the case of unfeeling plants or animals (though it may matter if it engenders or affects the welfare of feeling individuals). That is why it is important to use welfare biology to help ascertain which species are sentient, hence capable of welfare (Ng 1995). Neither "intelligence" (i.e., performance capacity) nor life alone is of intrinsic moral significance; only the capacity for suffering or enjoying (i.e., feeling) matters morally. This is the importance that underlies the name of this journal: Animal Sentience.

- "Ng seems unconcerned about mass extinctions..." (Lori Marino). This is clearly a gross misinterpretation of my position. There are some who believe that "Habitat destruction, not preservation, generally reduces wild-animal suffering" (Tomasik 2016). But though I am concerned with likely negative animal welfare, I am hoping for future salvation after significant scientific, economic, and ethical advances (Ng 1995). Thus, in contrast to Tomasik, I am not in favour of habitat destruction and/or mass extinctions - not to mention the likely threat that habitat destruction and mass extinctions due to our man-

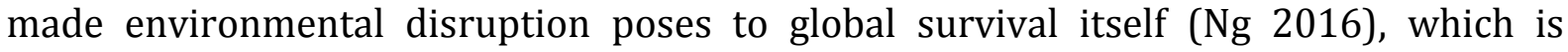
clearly very bad even just for human welfare.

- Stephen Clark mentions "the freedom to express normal behaviour," one of the "Five Freedoms" identified by the United Kingdom's Farm Animal Welfare Council (FAWC 2009). I wish to add here that "the freedom to express normal behaviour" may not be enough if Tomasik (2016) and I are right that most animals in the wild with their normal freedom to express normal behaviour may still have more suffering than enjoyment. We would have the moral obligation to reduce their suffering if we could do that safely, especially if it could be done at only moderate cost to humans. A person has the moral responsibility to help a fellow human in great danger or suffering if it could be done without too much danger and cost. A similar (perhaps slightly higher degree of) morality requires the extension of this help to animals. However, I think this should largely be left to the future, after there have been significant scientific and economic advances in the means of ensuring safety, for both animals and humans.

- I am in almost full agreement with Catia Faria. However, I have not changed my views since 1995 as she seems to argue or imply. My 1995 paper tries to provide some basics for welfare biology, with a conclusion on the likely negative welfare in the animal world. My 2016 target article discusses some short-term tactics for achieving successes in reducing animal suffering. Whereas they tackle largely separate (though related) issues, both articles are fully consistent with one another; I have not been converted to "the idyllic view of nature." In particular, the 2016 target article focuses on farmed animals but, as in 1995, does not exclude doing research now "on how to make it more feasible to carry out future long-term sustained interventions to benefit wild animals" and to help make people aware of huge animal suffering both in the food industry and in the wild. I still think it prudent, however, to leave actual large-scale interventions in the wild largely to the future.

- Similarly, my agreement with Oscar Horta's commentary would become complete if he just added the qualification (which I always used in my target article) "largely" to his clause describing my position: "leaving for the future the protection of animals in the wild." (This qualification also makes it unnecessary to amend my "strategical 
viewpoint.") I am very much in favour of raising awareness of animal suffering and helping animals even in the wild now; it is just that the large-scale attempts to raise animal welfare towards a positive level have to wait for great improvements in our capabilities, including our moral awareness and practices. Thus, the efforts of animal advocates and animal scientists are very important. Cooperation and persuasion are usually more fruitful than fighting one another.

- Somewhat similarly, temporary priority in dealing with farmed animals does not preclude the "variety and pluralism" favoured by Beril Sözmen. Almost everyone would favour doing animal research without inflicting pain on animals wherever possible. But it may not be possible at all times. We view someone sacrificing herself voluntarily to defend her country from unjust invasion as heroic. The suffering incurred or the lives given up serve a greater cause. If some pain in some animals now could lead to a much greater reduction in suffering in the future, perhaps they may similarly be regarded as worthwhile? The difference is of course absence of consent. However, the question of consent and rights for animals vs. humans raises complex issues that are beyond the scope of this response. In simple terms, I still adhere to welfarism and utilitarianism, but the related issues are complex, including indirect effects and differences in the capabilities for consent, responsibility, and rights.

- In his short commentary, Daniel Dorado makes an important point. I assume that ecosystem conservation is desirable. Yet I do not believe in the value of ecosystems per se or even of life itself: only sentience matters intrinsically and ultimately. Thus, conservation is of value only if enjoyment prevails over suffering. This, however, sounds like the opposite of an important conclusion in my 1995 paper concerning the likely predominance of suffering in the animal world, as Dorado sharply and correctly observes. I have not changed my mind since 1995; everything there stands. The apparent inconsistency is explained as follows: While the animal world exclusive of humans is probably dominated by suffering (which, incidentally, should increase our responsibility to help them), the lucky homo sapiens largely have positive net welfare, as indicated (but not conclusively proven, due to some inadequacies in happiness measurement; see Ng 1996) by happiness studies (Diener et al. 2010, Ng 2013). As animals outweigh humans in number, their net suffering may outweigh our net welfare. However, before we go along with Tomasik (2016) in promoting habitat destruction (as discussed above), surely we should give the benefit of the doubt to the possibility of reversing the net welfare imbalance. More important, my own pro-conservation stance is based on optimism about future economic, scientific, and moral advances (perhaps quite far away, but destined to last far longer). These could improve conditions so as to confer positive net welfare on most animals (starting now with our farmed animals). This way conservation would be consistent with the moral stance that only sentience matters.

Last, I wish to thank the commentators for their support and suggestions, including particularly:

- "Family squabbles aside, I would like to express my thanks to Prof. Ng for opening a new doorway into the study and actualization of animal welfare" (Bernard Rollin). 
- "Making science and industry humane will take time, but Ng's welfare biology is a step in the right direction" (Peter Li).

- "If we strive towards a more rational ethics, free of bias, the importance of welfare biology will become clear and we will become more effective in reducing all kinds of suffering. Ng has made an important contribution to this effort" (Stijn Bruers).

- "Ng should be commended for his progressive and yet cautious stance towards suffering in the wild, a topic that has only recently begun to attract much philosophical attention" (Kyle Johannsen).

Let us continue working towards increasing welfare (human and animal), reducing suffering in particular, using appropriate measures, including safeguarding certain animal rights. However, the rights should be designed to increase net welfare overall, not rights for rights' sake. I hope this could serve as the common conceptual ground for most animal advocates.

\section{References}

Arnold, B. C. (2015). Pareto distribution. Wiley.

Baker, L. (2016). What's the common sense of just some improvement of some welfare for some animals? Animal Sentience 2016.068

Bekoff, M. \& Pierce, J. (2016). Animal welfare cannot adequately protect nonhuman animals: The need for a science of animal well-being. Animal Sentience 2016.067

Bruers, S. (2016). Animal suffering and human bias. Animal Sentience 2016.084

Clark, S. R. (2016) Slavery, welfare and the sixth extinction. Animal Sentience 2016.089

Cowen, T. (2005). What a non-Paretian welfare economics would have to look like. In Lavoie, D. (Ed.), Economics and hermeneutics. Routledge.

Dawkins, M. (2014). Animal welfare and the paradox of animal consciousness. Advances in the Study of Behavior, 47, 1-34.

Dennis, W. (Ed.). (1948). Readings in the history of psychology (pp. 155-156). Century psychology series. Appleton-Century-Crofts.

Diener, E., Kahneman, D. \& Helliwell, J. (2010). International differences in well-being. Oxford: Oxford University Press.

Dorado, D. (2016). Sentience as moral consideration and disvalue in nature. Animal Sentience 2016.096

Edgeworth, F. Y. (1881). Mathematical psychics. London: Kegan Paul. 
Faria, C. (2016). Why we should not postpone awareness of wild animal suffering. Animal Sentience 2016.091

Harnad, S. (2016). My orgasms cannot be traded off against others' agony. Animal Sentience 2016.097

Horta, O. (2016) Changing attitudes towards animals in the wild and speciesism. Animal Sentience 2016.092

Jacques, S. (1979). Brain stimulation and reward:" pleasure centers" after twenty-five years. Neurosurgery, 5(2), 277-283

Johannsen, K. (2016) Animal welfare at home and in the wild. Animal Sentience 2016.085

Leadbeater, S. R. B. (2016). Animal suffering calls for more than a bigger cage. Animal Sentience 2016.071

Li, P. J. (2016). Animal suffering in China. Animal Sentience 2016.078

Lin, D. (2016). What is welfarism?

Marino, L. (2016). Why animal welfarism continues to fail. Animal Sentience 2016.074

Marks, J. (2016). End-state welfarism. Animal Sentience 2016.075

Ng, Y-K. (1975). Bentham or Bergson? Finite sensibility, utility functions, and social welfare functions, Review of Economic Studies, 42, 545-570.

Ng, Y-K. (1983). Some broader issues of social choice. In P. K. Pattanaik and M. Salles (Eds.), Social choice and welfare (pp. 151-174). Amsterdam: North Holland.

Ng, Y-K. (1989). What should we do about future generations? The impossibility of Parfit's theory X. Economics and Philosophy, 5, 135-253.

Ng, Y-K. (1990). Welfarism and utilitarianism: A rehabilitation. Utilitas, 2(2), 171-193.

Ng, Y-K. (1992). Utilitarianism and interpersonal comparison: Some implications of a materialist solution to the world knot, Social Choice and Welfare, 1992, 9(1), 1-15.

Ng, Y-K. (1996). Happiness surveys: Some comparability issues and an exploratory survey based on just perceivable increments." Social Indicators Research, 38(1), 1-27.

Ng, Y-K. (2004a). Welfare economics: Towards a more complete analysis. London: Palgrave/Macmillan. 
Ng, Y-K. (2004b). Optimal environmental charges/taxes: Easy to estimate and surplusyielding. Environmental and Resource Economics, 28(4), 395-408.

Ng, Y-K. (2005). Intergenerational impartiality: Replacing discounting by probability weighting. Journal of Agricultural and Environmental Ethics, 18(3), 237-257.

Ng, Y-K. (2013). The road to happiness. Fudan University Press. (In Chinese).

$\mathrm{Ng}, \mathrm{Y}-\mathrm{K}$. (2015). Some conceptual and methodological issues on happiness: Lessons from evolutionary biology. Singapore Economic Review, 2015, 60(4).

Ng, Y-K. (2016). The importance of global extinction in climate change policy, Global Policy, in print.

Ng, Y-K. (2016) How welfare biology and commonsense may help to reduce animal suffering. Animal Sentience 2016.007

Paez, E. (2016). Wild animal suffering and vegan outreach. Animal Sentience 2016.087

Pigou, A. C. (1912/1929/1932). Wealth and welfare. Later editions $(1920,1924,1929,1932)$ assume the title The economics of welfare. London: Macmillan.

Rollin, B. E. (2016). Science and sensibility. Animal Sentience 2016.077

Smith, A. M. \& Reese, J. (2016). An empirical perspective on animal advocacy. Animal Sentience 2016.088

Sözmen, B. (2016). Inalienable rights and pluralism in animal advocacy. Animal Sentience 2016.094

Tomasik, B. (2016). Habitat destruction, not preservation, generally reduces wild animal suffering.

Weber, E. H. (1834). De tactu [concerning touch], trans. W. Dennis (1948). 